\title{
Cohesive Devices in the United Nations Arabic Texts and their English Translations: A Corpus-based Study
}

\begin{abstract}
:
This paper examines one essential aspect of equivalence in translation: textual cohesion. It aims to contrast Arabic and English cohesive devices in some United Nations texts, find out how they are interpreted as equivalents and examine the regularity in shifting cohesion. A parallel corpus of texts of 15 Arabic texts and their English translation counterparts are selected and the distribution of their cohesive devices is analysed. Using computer software, the use of cohesive devices is compared. Findings reveal that Arabic and English have more similarities than differences in terms of the cohesive devices used though there are obvious differences in the frequency of their occurrence. The similarities are significantly preserved for the purpose of accurateness, transparency and formality that characterise the language of legal texts.
\end{abstract}

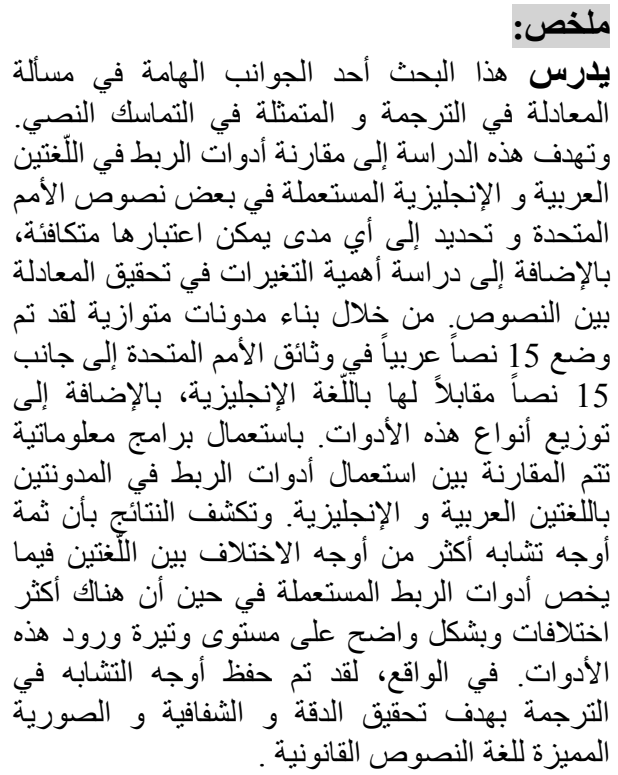

(c) Université des Frère Mentouri Constantine, Algérie, 2016.

\section{Introduction :} Nations Texts.

\section{Imen CHAALAL}

Faculty of Letters and Languages

Department of Letters and English

University of Mentouri

Constantine

Nowadays, the accelerated phenomenon of globalization has significantly affected the fields of translation, contrastive studies and corpora, and has allowed them to gain popularity more than ever. Scholars working in these fields, especially Baker [1], are credited for pushing these areas towards empirical, interdisciplinary and multilingual investigations. Hence, translation and parallel corpora are conjoined together in order to undergo a contrastive study of Arabic and English cohesive devices used in some United 
In the history of contrastive studies, the focus had always been on the microlinguistic approach to language, i.e. the analysis of grammar, phonology and lexis. However, with the development of linguistic studies, contrastive studies became more concerned with macro-linguistic analyses, i.e. the study of discourse analysis and text linguistics. As a result, the shift of interest from words in isolations to whole texts found also its way in translation studies. Henceforth, the topic of cohesion was introduced because it plays a significant role in the organisation of unified texts, and became one major topic of text translation. Newmark [2] as cited in Baker [3:180] pointed out that "the topic of cohesion... has always appeared to me the most useful constituent of discourse analysis or text linguistics applicable to translation."

During the process of translation, it is inevitably important to add or to omit parts of text in order to maintain its cohesiveness; such changes are generally known as shifts of cohesion which help translators to create accurate and natural translation products. Based on Halliday and Hasan's model of cohesion [4], the study attempts to observe variation in the way each language makes use of cohesive devices to signal cohesion relations and to identify the shift of cohesion, at the textual level, in the English translations of some Arabic United Nations texts.

The questions asked are whether the diverse grammatical and lexical structures of Arabic and English exhibit different types of cohesive devices in translation, and whether there are any significant differences in the frequency of occurrence of these devices across the two languages. The focus, then, will be on the distribution of grammatical and lexical cohesion in the translated text and the examination of how these devices can render the source language texts and the target ones into both cohesive and coherent products. Thus, by adopting the notion of translation equivalence as the best basis for contrastive analysis, the study aims basically (1) to scrutinise the behaviour of cohesive devices across the two languages and note to what extent they are interpreted as equivalents and (2) to examine, occasionally, the occurring patterns of shifts of cohesion in the translation product. Moreover, based on the assumption that the contribution of corpus-based studies in contrastive studies may be used for practical purposes in translation, and grounded on the very significant role of parallel corpora in the examination of the differences and similarities between languages, this research makes use of a unidirectional parallel corpus of Arabic and English United Nations texts.

\section{Textual Cohesion}

The last few decades have witnessed a growing interest in the application of discourse analysis and text-linguistics theories on translation studies. This 


\section{Cohesive Devices in the United Nations Arabic Texts and their English}

Translations: A Corpus-based Study

increased propensity fostered linguists to scrutinise aspects of cohesion in translation. While first eminent scholars such as de Beaugrande and Dressler [5] and Halliday and Hasan [4] defined cohesion in one single language, English, some others like Baker [3], Hatim and Mason [6] and Blum-kulka [7] defined cohesion in translation studies.

The concept of cohesion as suggested by Halliday and Hasan [4] and later on developed by Halliday [8] has played an important role in discourse analysis and text-linguistics. These two fields emphasise on one major argument: that any piece of text or discourse is produced for a specific function, either to inform readers or to persuade them; what is important is that writers use the texts' structures and semantic wholeness to achieve one particular goal. Following this view and in their influential work, Halliday and Hasan [4] proposed the concept of texture referring to the "property of being a text" [4: 2]. According to them, every text has its own features of organisation that help people distinguish between a text and a random collection of sentences. That is to say, by means of cohesive ties, people do relate sentences in a particular sequence in order to convey their intended meaning. Cohesion, thus, is an indispensable element to provide texture; it is a semantic relation which is classified in details into five types: reference, conjunction, ellipsis, substitution and lexical cohesion. Halliday [8: 311] argued that cohesion is one aspect of the study of texture and maintained that:

It is important to be able to think of text dynamically, as an ongoing process of meaning; and of textual cohesion as an aspect of this process, whereby the flow of meaning is channelled into a traceable current of discourse instead of spilling out formlessly in every possible direction.

Similarly, de Beaugrande and Dressler [5] proposed that for a piece of writing to be considered a text, it must meet seven standards of textuality; otherwise the text cannot be considered communicative. Cohesion, thus, is made as one of seven standards of textuality: cohesion, coherence, intentionality, acceptability, informativity, situationality, and intertextuality. They explained that cohesion:

Concerns the ways in which the components of the SURFACE TEXT, i.e. the actual words we hear or see, are mutually connected within a sequence. The surface components depend upon each other according to grammatical forms and conventions, such that cohesion 
rests upon GRAMMATICAL DEPENDENCIES.... All of the functions which can be used to signal relations among surface elements are included under our notion of COHESION. (9: 30)

Therefore, being a necessary element in the creation of texts, cohesion strongly influences the quality of the translation product. The significance of this concept in the framework of translation studies has been discussed by many researchers from different perspectives, for example: Baker [3], Blum-Kulka [7], and Hatim and Mason [6].

Baker [3], for example, reiterated that the main goal of translators is to guarantee a degree of equivalence at the textual level, rather than at the word or sentence level. According to her, translators intend to produce natural translated texts that are fluent and accurate without appearing foreign versions. That is why translators are requested to adjust some of the features existing in the source text in order to fit the organisation of the target texts.

Hatim and Mason [6], as well, maintained that translators should consider the texture features existing in each language while interpreting the communicative meaning. According to them, cohesive devices are language specific because of the languages' different origins; that is why, they may pose great challenges for translators. They expressed this as follows:

The various activities of translation criticism, translation assessment and revision all run the risk of concentrating on features of texture without relating them to the communicative process which engendered them. Texture needs to be seen an integral part of what one is doing with one's language. (6: 194)

In her discussion on shifts in cohesion, Blum-kulka [7:17] defined cohesion as "an overt relationship holding between parts of the text, expressed by language specific markers." She postulated one main argument adopted from the idea that the process of translation necessarily involves shifts in textual and discoursal relationships. Her argument is grounded on the perception that translation is viewed as an act of communication, and, therefore, all differences connected to both linguistic and cultural aspects holding between the two languages must be taken into consideration.

According to her, shifts of cohesion are evident in translation and fall into two types: shifts in levels of explicitness and shifts in meaning. In the first type, she explained that cohesive explicitness refers to shifts in the type of cohesive devices used. These shifts are achieved through the substitution of cohesive 


\section{Cohesive Devices in the United Nations Arabic Texts and their English}

Translations: A Corpus-based Study

devices with some others which do increase the level of cohesion in the target text. In the second type, i.e. shifts in meaning, she explained that the translation product demonstrates a change in the explicitness and implicitness of the meaning of the source text. Factors that explain these phenomena are explication, stylistic preferences or culture-bound translation norms.

Blum-kulka [7: 19] indicated that:

On textual level, shifts in levels of explicitness through translation have been claimed to be linked to differences in stylistic preference for types of cohesive markers in the two languages involved in translation.

And because in any language transfer there is a tendency to explicate, this strategy has been postulated as a universal strategy used by both novice and professional translators. Blum-kulka [ibid: 21] noted that "explication is a universal strategy inherent in the process of language mediation, as practiced by language learners, non-professional translators and professional translators alike."

All in all, it might be said that the aforementioned studies revealed the significance of the concept of cohesion within the framework of translation studies. They showed elaborately how the significant role of cohesion in organising the linguistic elements into unified texts became very pertinent to the study of translation.

\section{Contrastive Analysis, Translation and Corpus-based Studies}

It is a common fact that any contrastive analysis emphasises on the so called tertium comparationis (TC). This means that any two languages must have some common measure by which they can be compared in order to display the similarities and differences, otherwise such a task will not be possible. On this basis, James [10] reached the conclusion that translation equivalence is the best TC for contrastive analysis. He asserted that "For two sentences from different languages to be translationally equivalent they must convey the same ideational and interpersonal and textual meanings" [James, 10: 178]. Therefore, by investigating textual equivalence in corpus based translation studies, this study will uncover clear differences and similarities between the cohesive ties across the two languages in terms of the categories used and their occurrence frequencies. 
In fact, the development of computer technology and the emergence of corpus linguistic studies have brought many advantages to the study of linguistics; in the sense that they have succeeded to provide significant help in drawing attention to the study of language in use rather than the study of linguistic systems in the abstract. According to Teubert [11], real language data displayed in the form of larger corpora were strongly needed to undergo adequate investigations. He [12:1] argued that "Today, the corpus is considered the default resource for almost anyone working in linguistics. No introspection can claim credence without verification through real language data. Corpus research has become a key element of almost all language study."

Likewise, Baker [1] anticipated that the wide accessibility of large corpora of original and translated texts, in addition to the advances of corpus-driven methodology would facilitate for translators to reveal "the nature of translated text as a mediated communicative event." [1: 243]. Following this prediction, many researchers, to name but a few, Ebeling [13], Johansson [14], and Mauranen [15] started to view the approach of corpus-based studies as a practical and a new successful way for both translation studies and contrastive linguistics. They approved, as well, the significance of parallel corpora for the study of specific language patterns cross-linguistically, and helped translators to simplify the understanding of source language texts and improve their production skills.

Although the application of corpus-based linguistics in translation studies received high attention in the last two decades; the type of translation corpora, however, was seriously questioned by some researchers. According to Teubert [16], translated texts do corrupt the language, and therefore, cannot create a consistent foundation for contrastive analysis. He stated:

Translations, however good and near-perfect they may be (but rarely are), cannot but give a distorted picture of the language they represent. Linguists should never rely on translations when they are describing the language. That is why translations have no place in reference corpora. (16: 250)

Nevertheless, the significance of translation corpora was defended by many others. Zanettin [17:21], for example, argued that:

A decision to exclude translations on the assumption that the language of translation "corrupts" the standard norm of reference does not seem to be justified by theoretical considerations. On the other hand, corpora designed to 


\section{Cohesive Devices in the United Nations Arabic Texts and their English Translations: A Corpus-based Study}

investigate regularities of translation usually include a translational subcorpus. This subcorpus can be compared with different types of subcorpora in the same language, whose design will depend on the purpose of the investigation.

In a similar vein, Mauranen [15: 161] stressed that, translation corpora "constitute a valuable source of evidence for contrastive research" as they provide "language that has been used in its normal communicative contexts by a large number of users" [Mauranen, 15: 161]. Therefore, it might be said that the use of translation corpora, also known as parallel corpora, offers practical and effective advantages for contrastive studies. In other words, they reveal clearly the differences and similarities between the two languages and display a solid foundation of comparison for the particular features involved in any two languages. Johansson [14: 4] stated that "[parallel corpora] give new insights into the languages compared -insights that are likely to be unnoticed in monolingual corpora". Also, Mauranen [15: 161] indicated that "a parallel corpus can capture relations of sense as well as form, which would be very hard to capture without such data."

Finally, it is worth mentioning that many researchers have presented different classifications of corpora .Types of corpora include monolingual, parallel, multilingual and comparable corpora. See: Zanettin [18], Laviosa [19], Fernandes [20], Johannson [21], and Biel [22]. The corpus under study is called a parallel corpus (Baker, [23] \& McEnery et al., [24]), and a translation corpus (Granger, [25] \& Johansson, [14]); or a translational corpus (Lauridsen, [26]). It is, in fact, the most common version, where only two languages are involved; one sub-corpus consists of original texts, for example in Arabic, while the other of translated texts in a different language, English.

\section{Methodology}

As pointed out above, although parallel corpora play a vital role in finding equivalents, some researchers, however, believed they may not be the most convenient source of data for translators. The main reason is that the difficulties encountered in the process of translation may distort the ultimate originality of the translation product and would, eventually, make the target texts less typical and lead readers to question their quality. Therefore, in order to avoid such a complication and reduce any shortcomings, we relied on authentic texts derived from the United Nations' documentation, and produced by reasonably competent professional translators. In this view, the samples 
given in Arabic and English will be derived from a unidirectional aligned Parallel Corpus of the United Nations Texts (PCUNTs). It is worth mentioning that presenting a set of aligned parallel texts, as Barlow [27] reiterated, is very remarkable because it helps users to see every sentence with its corresponding translation, and therefore, to compare the translated texts with their originals.

\section{The Parallel Corpus of United Nations Texts (PCUNTs)}

\section{Selection of Texts for the Parallel Corpus (PCUNTs)}

The texts were selected according to their reputation and availability. They were exclusively derived from UN resolutions issued by the Security Council and the General Assembly; the two main organs of UN organisations and institutions. Based on the assumption that the translations of UN bodies are of great proficiency and of a high degree of reliability, the sample texts were selected. In terms of availability, the texts are available online and downloadable via the official website of UN Documentation ${ }^{(1)}$ (The ODS).

This parallel corpus (PCUNTs) consists of nine UN General Assembly Resolutions and six Security Council Resolutions published over a period of three years (2011-2013), and related to the most relevant events in the Middle East and North Africa, tackling mainly issues related to the crises in Syria and Libya. The contents of the parallel corpus are summarised in Table1. The parallel corpus encompasses a total of 30 texts, organised in an aligned paragraph pattern where the Arabic sub-corpus is established along with its translational counterpart in English. That is to say, 15 Arabic original texts and 15 English parallel translations are covered. The wording of texts ranges from 200 to 2000 running words per text. The whole corpus contains around $(36,903)$ word tokens; the Arabic sub-corpus has slightly fewer word tokens $(16,635)$ in comparison to the English one, $(20,268)$ word tokens. Because cohesive devices tend to be more frequent in the corpus, it might be said that such a relatively small corpus is sufficient and seems to be adequate for the purpose of analysis.

Furthermore, since the present study is based on the model of Halliday and Hasan [4], it is important to emphasise that cohesive devices between sentences are "the only source of texture" [4: 9], and, that "it is the inter-sentence cohesion that is significant, because that represents the variable aspect of cohesion, distinguishing one text from another" [Halliday \& Hasan, 4: 9]. However, in this paper, the analysis of cohesion is not merely restricted to inter-sentential ties for one main reason: that the punctuation system in Arabic and English is very flexible, and the notion of sentence boundaries is not 
specific. For example, one whole paragraph in Arabic may contain one single sentence, whereas its translational counterpart in English definitely differs. Accordingly, the analysis of cohesive devices within sentences, i.e. at the intrasentential level, is to be covered as well.

\begin{tabular}{|c|c|c|c|c|c|}
\hline UN Texts & $\begin{array}{l}N^{\circ} \text { of } \\
\text { Texts }\end{array}$ & Topics & $\begin{array}{c}\text { Word } \\
\text { Tokens } \\
\text { in } \\
\text { AUNTs }\end{array}$ & $\begin{array}{c}\text { Word } \\
\text { Tokens } \\
\text { in } \\
\text { EUNTs }\end{array}$ & $\begin{array}{c}\text { Year of } \\
\text { Publications }\end{array}$ \\
\hline $\begin{array}{l}\text { Security } \\
\text { Council } \\
\text { Resolutions }\end{array}$ & 6 & $\begin{array}{l}\text { Identical letters } \\
\text { from the } \\
\text { Permanent } \\
\text { Representative of } \\
\text { the Syrian Arab } \\
\text { Republic to the } \\
\text { United Nations } \\
\text { addressed to the } \\
\text { Secretary-General } \\
\text { and the President } \\
\text { of the Security } \\
\text { Council. } \\
\text { Letters from the } \\
\text { Permanent } \\
\text { Representative of } \\
\text { Libya to the United } \\
\text { Nations addressed } \\
\text { to the President of } \\
\text { the Security } \\
\text { Council. }\end{array}$ & 9,589 & 12,037 & $2011-2013$ \\
\hline $\begin{array}{l}\text { General } \\
\text { Assembly } \\
\text { Resolutions }\end{array}$ & 9 & $\begin{array}{l}\text { Reports of the } \\
\text { Secretary-General } \\
\text { concerning the } \\
\text { situation in the } \\
\text { Middle East: } \\
\text { Replies received } \\
\text { from the Syrian } \\
\text { Arab Republic. } \\
\text { Letters from the }\end{array}$ & 7,046 & 8,220 & 2011-2013 \\
\hline
\end{tabular}


Permanent

Representative of

the Syrian Arab

Republic to

the United Nations

addressed to the

Secretary-General.

Annexes to letters

from the

Permanent

Representative of

the Syrian Arab

Republic to the

United Nations

addressed to the

Secretary-General.

$\begin{array}{llll}\text { Total } & 15 & 16,635 & 20,268\end{array}$

Table 1: Summary of the Corpus of United Nations Texts

\section{Tools and Procedure of Analysis}

For the purpose of analysis, we used two main software tools developed by Laurence Anthony ([28] \& [29]). First, the AntConc (Anthony Concordancer) software (Anthony, [28]) is used; the word list function of the AntConc allows us to create the list of the most frequent cohesive devices in the parallel corpus (PCUNTs), and to compare the two sub-corpora in terms of the types of cohesive devices used. Second, the AntPconc (Anthony Parallel Concordancer) software (Anthony, [29]) is used in order to examine the differences and similarities between Arabic and English cohesive devices. Through the parallel concordance function of the AntPconc, the samples allow us to distinguish the differences in real context, and therefore, to detect any shift of cohesive patterns in the translated corpus.

Therefore, with the help of these two software tools (Anthony, [28] \& [29]), all the cohesive devices in Arabic and English texts are computed and the types of cohesive devices in the two sub-corpora are identified according to the taxonomy of Halliday and Hasan [4], as in Table 2. Then, the total number of all types of cohesive devices in Arabic United Nations Texts (AUNTs) and English United Nations Texts (EUNTs) are compared, and run in SPSS 22 software (Statistical Package for the Social Sciences). 


\begin{tabular}{ll} 
Types & \multicolumn{1}{c}{ Subcategories of Cohesive Devices } \\
\hline Reference & $\begin{array}{l}\text { R.1 Pronominals, R.2 Demonstratives and Definite Article } \\
\text { 'the', } \\
\text { R.3 Comparatives }\end{array}$
\end{tabular}

\begin{tabular}{ll}
\hline Substitution & $\begin{array}{l}\text { S.1 Nominal Substitute, S.2 Verbal Substitute, S.3 Clausal } \\
\text { Substitute }\end{array}$ \\
\hline Ellipsis & E.1 Nominal Ellipsis, E.2 Verbal Ellipsis, E.3 Clausal Ellipsis
\end{tabular}

Conjunctions C.1 Additive, C.2 Adversative, C.3 Causal, C.4 Temporal, C.5 Other Types

Lexical LC.1 Reiteration: Repetition, Synonymy or Near Synonymy,

Cohesion Superordinate or Hypernyms, General Term.

LC.2 Collocation: Relation of Antonomy, Relation of

Complementarity, Relation of Part to whole or Meronymy,

Relation of part to part. Relation of Co-hyponymy, Words

from the same ordered series.

Table 2: Summary of Cohesion and Coding Scheme (Halliday \& Hasan,

[4])

\section{Results and Discussion}

\section{Distribution and Comparison of Cohesive Devices}

The overall frequency and distribution of the identified cohesive devices across the two sub-corpora (AUNTs) and (EUNTs) are sorted out in Table 3. The figures listed in the table below showed a total of 7963 of the five types of cohesive devices in AUNTs, whereas EUNTs showed a total of 6456. 


\begin{tabular}{lcccc}
$\begin{array}{l}\text { Corpus } \\
\begin{array}{l}\text { Cohesive } \\
\text { Devices }\end{array}\end{array}$ & $\begin{array}{c}\text { AUN Texts } \\
\text { Occurrences }\end{array}$ & $\begin{array}{c}\text { Percentage } \\
\%\end{array}$ & $\begin{array}{c}\text { EUN Texts } \\
\text { Occurrences }\end{array}$ & Percentage \% \\
\hline Reference & 2222 & 27.90 & 957 & 14.82 \\
\hline Substitution & 141 & 01.77 & 156 & 02.41 \\
\hline Ellipsis & 16 & 00.20 & 50 & 00.77 \\
\hline Conjunction & 1703 & 21.38 & 1359 & 21.05 \\
\hline $\begin{array}{l}\text { Lexical } \\
\text { Cohesion }\end{array}$ & 3881 & 48.73 & 3934 & 60.93 \\
\hline Total & $\mathbf{7 9 6 3}$ & $\mathbf{1 0 0 \%}$ & $\mathbf{6 4 5 6}$ & $\mathbf{1 0 0 \%}$
\end{tabular}

Table 3: Frequencies and Percentages of Cohesive Devices

The word frequency analysis revealed that the two sub-corpora followed different decreasing orders in terms of their frequencies. In the (AUNTs), lexical cohesion was the most frequently used device $(48.73 \%)$ followed by reference $(27.90 \%)$ and conjunction $(21.38 \%)$. Both substitution $(01.77 \%)$ and Ellipsis $(0.20 \%)$ appeared with very low frequencies. Unlike the (AUNTs), the mostly used devices in (EUNTs) were lexical cohesion (60.93\%), followed by conjunction $(21.05 \%)$ and then reference $(14.82 \%)$.Similar to (AUNTs), both substitution $(02.41 \%)$ and ellipsis $(0.77 \%)$ were of low frequencies. Thus, it can be said that the three mostly used cohesive devices were lexical cohesion, reference and conjunctions. The distribution of these devices in the two subcorpora displayed many similarities in the choice of the types of cohesive devices, though the differences occurred in the second most frequent type of cohesive devices. AUNTs exhibited a preference for reference while EUNTs showed preference for conjunctions. However, both substitution and ellipsis were of little use and were considered as marginal phenomena in the two subcorpora.

Because United Nations texts are descriptive and argumentative in nature aiming at presenting facts and persuading readers, lexical cohesion plays a vital role in the organisation of information. Besides, like all legal texts, UN texts are very formal and always require a lot of transparency, precision and accurateness; these characteristics explain overtly the scarce use of substitution and ellipsis which may cause misunderstanding and ambiguity. 


\section{Cohesive Devices in the United Nations Arabic Texts and their English}

Translations: A Corpus-based Study

\section{Distribution of the Subcategories of Conjunctions}

Table 4 below provides a summary of conjunctive cohesion in the two subcorpora. The table displays the five types of conjunctions, their number of occurrences and percentages in AUNTs and EUNTs.

Table 4: Frequencies and Percentages of the Subcategories of

\begin{tabular}{|c|c|c|c|c|}
\hline \multirow{2}{*}{$\begin{array}{l}\text { Corpus } \\
\text { Conjunctive } \\
\text { Devices }\end{array}$} & \multicolumn{2}{|c|}{ AUN Texts } & \multicolumn{2}{|c|}{ EUN Texts } \\
\hline & $\begin{array}{c}\mathrm{N}^{\circ} \text { of } \\
\text { Occurrences }\end{array}$ & $\begin{array}{c}\text { Percentage } \\
\%\end{array}$ & $\begin{array}{c}\mathrm{N}^{\circ} \text { of } \\
\text { Occurrences }\end{array}$ & Percentage $\%$ \\
\hline Additive & 1408 & 82.67 & 1062 & 78.14 \\
\hline Adversative & 37 & 02.17 & 25 & 01.83 \\
\hline Causal & 97 & 05.69 & 90 & 06.62 \\
\hline Temporal & 82 & 04.81 & 72 & 05.29 \\
\hline Others & 79 & 04.63 & 110 & 08.09 \\
\hline Total & 1703 & $\begin{array}{c}100 \% \\
\text { Conjunction }\end{array}$ & 1359 & $100 \%$ \\
\hline
\end{tabular}

A glance at the table reveals that additives $(82.67 \%$ in AUNTs and $78.14 \%$ in EUNTs) are by far the most frequent devices of conjunctions, followed by causals $(05.69 \%$ in AUNTs and $06.62 \%$ in EUNTS) and temporals $(04.81 \%$ in AUNTs and $05.29 \%$ in EUNTs). Adversatives (02.17\% in AUNTs and $01.83 \%$ in EUNTs), however, were found to be the least frequently used in the PCUNTs. Other types of conjunctions i.e. continuative conjunctions (04.63\% in AUNTs and $08.09 \%$ in EUNTs) were of very low frequencies in AUNTs, whereas in EUNTs they were found in the third rank.

The nature of UN documents (resolutions), which is typically descriptive and rigid, explains the remarkable predominance of additives in the PCUNTs. Moreover, the importance given to causals and temporals in the second and third ranking respectively in AUNTs is due to, first, the argumentative characteristics of UN texts that aim to persuade readers, and, second, to their narrative function of successions of facts, events or precise reports that have taken place. The highly use of continuatives in EUNTs justifies the importance of logical relations in English United Nations texts. That is to say, English highlights the explicit means to show semantic relations at the inter-sentential level, that is why continuatives are highly employed. Continuatives like regarding and with reference to are maintained in English in order to show clearly the semantic relations of sequence. 
On the whole, conjunctive devices were utilised in AUNTs as frequently as in EUNTs. No significant difference was found in the first four subcategories in terms of their occurrence $(\mathrm{p}>0.05)$, but there was a significant difference in the statistical result of continuatives $(\mathrm{p}=0.002<0.05)$. The paired samples $t$-test results are presented in Table 5 below.

Table 5: T-test Results for of the Subcategories of Conjunctions

\begin{tabular}{lccccc}
$\begin{array}{l}\text { Conjunctive } \\
\text { Devices }\end{array}$ & Mean & $\begin{array}{c}\text { Std. } \\
\text { Deviation }\end{array}$ & t & df & $\begin{array}{c}\text { Sig.(2- } \\
\text { tailed) }\end{array}$ \\
\hline Additive & 23.06667 & 23.14386 & 3.860 & 14 & 0.066 \\
\hline Adversative & 0.80000 & 3.36367 & 0.921 & 14 & 0.373 \\
\hline Causal & 0.46667 & 3.35659 & 0.538 & 14 & 0.599 \\
\hline Temporal & 0.86667 & 6.33434 & 0.530 & 14 & 0.604 \\
\hline Continuatives & -2.06667 & 4.00832 & -1.997 & 14 & 0.002 \\
\hline
\end{tabular}

The wordlist function of the AntConc Software tool (Anthony, [28]) revealed that the most remarkable difference between the two sub-corpora lies in the frequency of additives $g w a$ (1333 word tokens) and and (908 word tokens) which are significantly different. In fact, Arabic $9 w a$ as shown in Figure 1 is the most frequent of all conjunctions in Arabic and ranks first in all Arabic words. Almost all linguists who approached Arabic were struck by its high frequency. Dudley-Evans and Swales ([30], cited in Al-Jaber [31]), for example, examined the redundancy of $9 w a$ in Arabic and explained that a number of factors contribute to its high frequency. Al-Jaber [31] summarised them as follows: First, the lengthy sentences that characterise Arabic generate the abundant use of $9 w a$. Also, the trend of Arabic towards using coordination as a favoured structural device enriched the use of conjunction $9 w a$. Moreover, the occurrence of $g w a$ with other conjunctions such as the additive يضاً and adversative لكن lakin, which is very usual, in Arabic enhances its frequency. Equally the conjunction and occurs with other conjunctions in English, for example and also, but does not occur with but. Therefore, this extensive usage of $9 w a$, in addition to its multifunctional nature working as causals, temporals or adversatives increases its frequency; this is also valid to the conjunction and but with lower frequencies. 

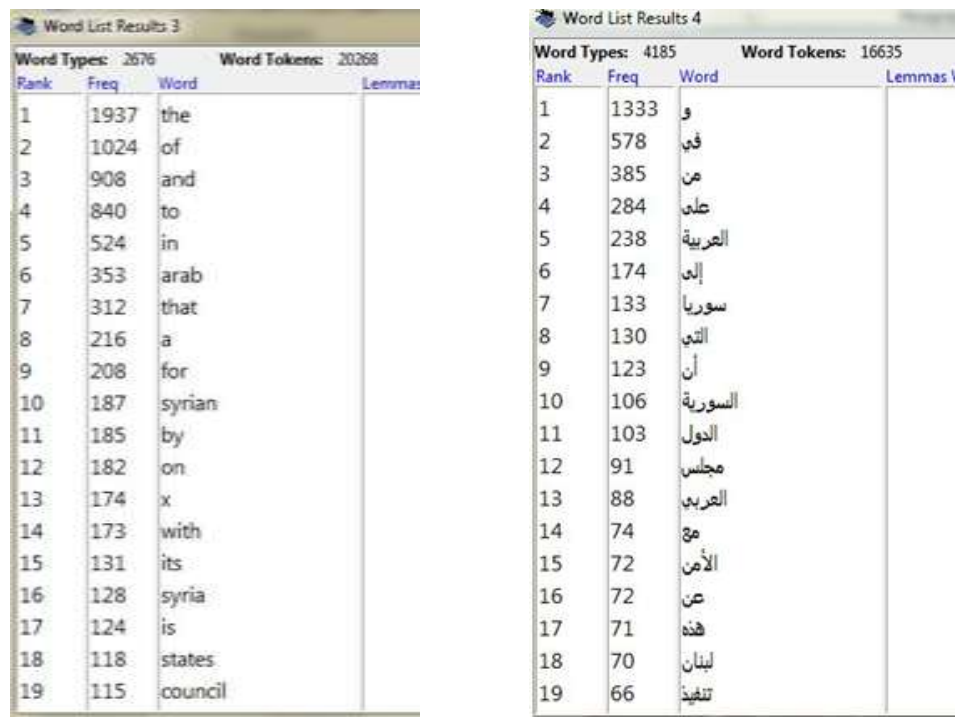

Figure 1: Most Frequent Words in the Two Sub-Corpora

\section{Distribution of the Subcategories of Reference}

As gleaned from Table 6, AUNTs exhibited a total of 2222 of four types of reference devices, whereas EUNTs showed a total of 957.

Table 6: Frequencies and Percentages of the Subcategories of Reference

\begin{tabular}{lcccc}
$\begin{array}{l}\text { Corpus } \\
\text { Reference }\end{array}$ & \multicolumn{2}{c}{ AUN Texts } & \multicolumn{2}{c}{ EUN Texts } \\
& $\begin{array}{c}\mathrm{N}^{\circ} \text { of } \\
\text { Occurrences }\end{array}$ & $\begin{array}{c}\text { Percentage } \\
\%\end{array}$ & $\begin{array}{c}\mathrm{N}^{\circ} \text { of } \\
\text { Occurrences }\end{array}$ & $\begin{array}{c}\text { Percentage } \\
\%\end{array}$ \\
\hline Pronominals & 1934 & 87.03 & 586 & 61.23 \\
\hline Demonstratives & 203 & 09.13 & 226 & 23.61 \\
\hline Comparatives & 75 & 03.37 & 113 & 11.80 \\
\hline Others & 10 & 00.45 & 32 & 03.34 \\
\hline Total & $\mathbf{2 2 2 2}$ & $\mathbf{1 0 0 \%}$ & $\mathbf{9 5 7}$ & $\mathbf{1 0 0 \%}$ \\
\hline
\end{tabular}

Detailed analysis showed that pronominals or personal reference $(87.03 \%$ in AUNTs and $61.23 \%$ in EUNTs) was the most prevalent subcategory of reference in the parallel corpus, followed by demonstratives $(09.13 \%$ in AUNTs and $23.61 \%$ in EUNTs) and then comparatives (03.37\% in AUNTs and $11.80 \%$ in EUNTS). Other types of reference including blend words and 
numbering references ${ }^{(2)}$, which characterise the language of legal texts, came out with very low frequencies $(0.45 \%$ in AUNTs and, $03.34 \%$ in EUNT). While AUNTs depend heavily on pronominals more than EUNTs do, demonstratives and comparatives are found in EUNTs more frequently than in AUNTs. Thus, it can be said that AUNTs are more explicitly cohesive than their English counterparts through the use of pronominals. EUNTs, however, exhibit more emphasis on repetition for the aim of accuracy instead of reference, as we will see later.

Despite the same distribution of the subcategories of reference, significant differences exist in the occurrence frequencies of two types of reference, Pronominals and others, between AUNTs and EUNTs $(\mathrm{p}=0.048<0.05$ and $\mathrm{p}=0.037<0.05$ respectively) as shown in table 7 below.

Table 7: T-test Results for the Subcategories of Reference

\begin{tabular}{lccccc} 
Reference & Mean & $\begin{array}{c}\text { Std. } \\
\text { Deviation }\end{array}$ & t & df & $\begin{array}{c}\text { Sig.(2- } \\
\text { tailed) }\end{array}$ \\
\hline Pronominals & 116.53333 & 208.31908 & 2.167 & 14 & 0.048 \\
\hline Demonstratives & -0.66667 & 21.06679 & -0.123 & 14 & 0.904 \\
\hline Comparatives & -2.86667 & 11.06388 & -1.003 & 14 & 0.333 \\
\hline Others & -2.06667 & 3.47371 & -2.304 & 14 & 0.037 \\
\hline
\end{tabular}

In fact, Arabic has three types of pronouns: independent, enclitic and implicit, in addition to special pronouns for the category of dual. English, however, does not have such a variety of pronouns. That is why pronominals are found considerably more in the Arabic texts. Williams [32] maintained that the high frequency of pronominals in Arabic texts is attributed to the nature of Arabic verbs which contain an implicit pronoun, in addition to their fully inflected nature for number and gender. Pronominals in Arabic, thus, obtain a greater referential significance more than their English counterparts. In this view, it can be said that the abundant use of pronominals in Arabic UN texts is a consequence of the legal texts' deep concern to preserve maximum levels of precision and reduce misunderstanding.

It is important to mention that the use of blend words, such as: hereby, herebelow, and herebefore are very essential to ensure the accuracy of legal texts. (Karakira, [33]). This kind of reference is widely utilised in UN texts. It is through a specific reference to the whole text or to any of its parts that textual cohesion is maintained in UN texts. An extract from the PCUNTs presenting the reference device herewith and its concordance list are displayed below: 


\section{Cohesive Devices in the United Nations Arabic Texts and their English}

Translations: A Corpus-based Study

I have the honour to transmit herewith a letter from H. E. Mr. WalidAl-Moualem, Minister for Foreign Affairs of the Syrian Arab Republic dated14 March 2011, addressed to the Secretary-General and the President of the Security Council, regarding the capture and imprisonment of the two Syrian citizens, Mr. Majed Al Chaer and Mr. Fidaa Chaer from the Occupied Syrian Golan, by the Israeli occupation authorities last year and the recent issuing of unjust judgments against them (see annex).

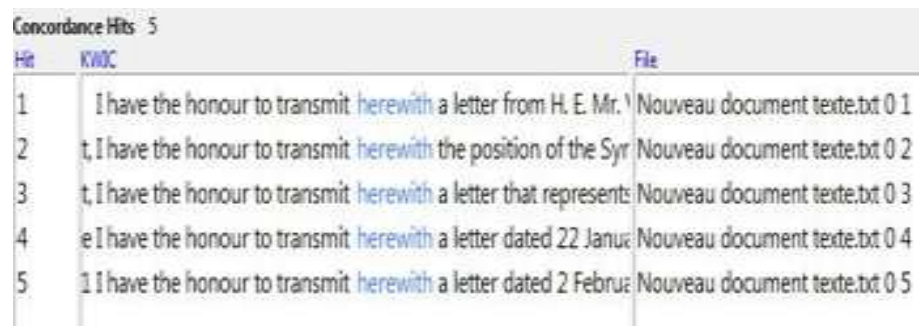

\section{Figure 2: Concordance Sample from PCUNTs for the Reference herewith}

Another cohesive device that is significant in United Nations texts is the feature of articulation and numbering. Karakira [33] asserted that because legal texts follow rigid methods of dividing documents into parts or paragraphs, references are clearly made throughout the text. Thus, it can be said that this elaborate referencing system within the one text is a strong cohesive feature shared by all legal texts. Accordingly, this type of cohesive reference is significantly found in this parallel corpus. These examples are extracted from the PCUNTs:

In resolution 65/18, the Assembly declared that the Israeli decision of 14 December 1981 to impose its laws, jurisdiction and administration on the occupied Syrian Golan was null and void and had no validity whatsoever, as confirmed by the Security Council in its resolution 497 (1981), and called upon Israel to rescind the decision.

Another example is: 
Arab Republic has also declared in all international forums its full commitment to the relevant international resolutions and has called for their implementation, in particular Security Council resolutions 242 (1967), 338 (1973) and 497 (1981).

These two passages explicitly display the use of articulation and numbering in the PCUNTs. The numbers of resolutions are significantly referring to specific and prior resolutions established by the United Nations authorities.

\section{Distribution of Substitution and Ellipsis}

Table 8: Frequencies and Percentages of Substitution and Ellipsis

\begin{tabular}{lcccc}
$\begin{array}{l}\text { Corpus } \\
\text { Cohesive } \\
\text { Devices }\end{array}$ & \multicolumn{2}{c}{ AUN Texts } & \multicolumn{2}{c}{ EUN Texts } \\
Nocurrences & $\begin{array}{c}\mathrm{N}^{\circ} \text { orcentage } \\
\%\end{array}$ & $\begin{array}{c}\mathrm{N}^{\circ} \text { of } \\
\text { Occurrences }\end{array}$ & Percentage \% \\
\hline Substitution & 141 & 01.77 & 156 & 02.41 \\
\hline Ellipsis & 16 & 00.20 & 50 & 00.77 \\
\hline
\end{tabular}

The table showed that substitution $(01.77 \%$ in AUNTs and $02.41 \%$ in EUNTs) and ellipsis $(0.20 \%$ in AUNTs and $0.77 \%$ in EUNTs) are quite infrequent in the two sub-corpora.

The scarcity of these devices in written discourse has been confirmed by many researchers. Williams [32], for example, pointed out that Arabic tends to avoid ellipsis. In this parallel corpus, both substitution and ellipsis are considered to be marginal phenomena in both Arabic and English United Nations documents; however, English tends to use them more frequently than Arabic. Such scarcity of use of these devices is due to the nature of the United Nations texts, which are particularly precise, aiming at achieving exactness of meaning and reducing any possible ambiguity that may affect the information.

\section{Distribution of Lexical Cohesion}

Table 9: Frequencies and Percentages of Lexical Cohesion

\begin{tabular}{lcccc}
$\begin{array}{l}\text { Corpus } \\
\text { Lexical } \\
\text { Cohesion }\end{array}$ & \multicolumn{2}{c}{ AUN Texts } & \multicolumn{2}{c}{ EUN Texts } \\
No of & $\begin{array}{c}\text { Percentage } \\
\text { Occurrences }\end{array}$ & $\begin{array}{c}\text { N }^{\circ} \text { of } \\
\text { Occurrences }\end{array}$ & Percentage \% \\
\hline Reiteration & 3437 & 88.55 & 3177 & 80.75 \\
\hline Collocation & 444 & 11.44 & 757 & 19.24 \\
\hline Total & $\mathbf{3 8 8 1}$ & $\mathbf{1 0 0 \%}$ & $\mathbf{3 9 3 4}$ & $\mathbf{1 0 0 \%}$ \\
\hline
\end{tabular}


As shown in Table 9, reiteration (88.55\% in AUNTs and $80.75 \%$ in EUNTs) was the dominant device of lexical cohesion in AUNTs and EUNTs in terms of occurrence frequencies, while collocation (11.44\% in AUNTs and $19.24 \%$ in EUNTs) showed a very low frequency. Significant differences were found in the occurrence frequencies of the two subcategories of lexical cohesion between AUNTs and EUNTs $(\mathrm{p}=0.006<0.05)$.

Table 10: T-test Results for Lexical Cohesion

\begin{tabular}{lccclc}
$\begin{array}{l}\text { Cohesive } \\
\text { Devices }\end{array}$ & Mean & $\begin{array}{c}\text { Std. } \\
\text { Deviation }\end{array}$ & t & df & $\begin{array}{c}\text { Sig. } \\
\text { (2-tailed) }\end{array}$ \\
\hline $\begin{array}{l}\text { Lexical } \\
\text { Cohesion }\end{array}$ & -26.50000 & 405.17219 & -0.092 & 1 & 0.006 \\
\hline
\end{tabular}

The data contained in table 9 above show that lexical reiteration is much more frequent in AUNTs, whereas lexical collocation is employed more frequently in EUNTs. Lexical reiteration contributes significantly to the cohesion of United Nations texts, in the sense that patterns of repetition, synonymy, or general words are included for the sake of emphasis and the guarantee of a consistent flow of ideas. As far as collocation is concerned, though it is much less used than reiteration in the two sub-corpora, it still plays a vital role at the inter-sentential level; it exceeds the boundaries of sentences and even paragraphs in order to guarantee the required accurateness and clarity of texts. Therefore, it can be said that lexical cohesion is achieved partly through reiteration and partly through collocation which are related to the nature of legal texts.

In what follows, repetition, the most prevailing type of lexical reiteration, will be discussed.

\begin{tabular}{|c|c|c|c|c|}
\hline Corpus & AUN & exts & EUI & Texts \\
\hline $\begin{array}{l}\text { Lexical } \\
\text { Cohesion }\end{array}$ & $\begin{array}{c}\mathrm{N}^{\circ} \text { of } \\
\text { Occurrences }\end{array}$ & $\begin{array}{c}\text { Percentage } \\
\%\end{array}$ & $\begin{array}{c}\mathrm{N}^{\circ} \text { of } \\
\text { Occurrences }\end{array}$ & Percentage $\%$ \\
\hline
\end{tabular}




\begin{tabular}{ccccc}
\hline Repetition & 2931 & 85.27 & 2649 & 83.38 \\
\hline \multicolumn{4}{c}{ Table 11: Frequencies and Percentages of Repetition }
\end{tabular}

From the table above, it is evident that the repetition patterns are the prevailing lexical cohesive devices used in the parallel corpus. The figures listed in the table show a total of 2931 of repetition in AUNTs, whereas EUNTs show a total of 2649. In other words, AUNTs (85.27\%) tend to use repetition more than their English counterparts (83.38\%). Significant differences exist in the occurrence frequencies of repetition between AUNTs and EUNTs ( $\mathrm{p}=$ $0.035<0.05)$.

Table 12: T-test Results for Repetition

\begin{tabular}{lccccc}
$\begin{array}{l}\text { Lexical } \\
\text { Cohesion }\end{array}$ & Mean & $\begin{array}{c}\text { Std. } \\
\text { Deviation }\end{array}$ & t & df & $\begin{array}{c}\text { Sig. } \\
\text { (2-tailed) }\end{array}$ \\
\hline Repetition & 25.46667 & 42.27777 & 2.333 & 14 & 0.035 \\
\hline
\end{tabular}

Thus, it can be said that lexical repetition is of a high frequency and inevitable in the organisation of UN texts across the two languages. As far as English is concerned, Wright and Hope [34] asserted that lexical explicitness, the most remarkable feature of texts, is contingent on lexical cohesion, particularly repetition rather than reference such as pronominals. Similarly, Arabic tends to favour lexical repetition; Williams [32:126] maintained that "in Arabic 'the same theme' is repeated in 'successive clauses....more frequently than English does, even when it is grammatically possible to omit it" (quoted in Al-Jaber, [31]). Moreover, Al-Jaber [31] explained that the tendency of Arabic texts to use lexical repetition very frequently is said to be due to the abundant word root which can generate many derivatives. For example, the words ${ }^{(3)}$ ta.cli:m, عالم ju.calim and sulim, are all derivatives of the word .cilm عurthermore, since there is a strong trend towards description and argumentation in United Nations texts, the use of lexical repetition which is ascribed to rhetorical devices, such as assertion and exaggeration aims at persuading readers. Koch [35] examined repetition in argumentative discourse. She wrote: "repetition of form and content yields much cohesion to Arabic texts. Repetition is a means of persuasion in Arabic argumentative discourse." (Koch, [35], quoted in Al-Jaber, [31:167])

To clarify the significance of repetition, an extract from the PCUNTs below shows the term Syria reappearing in every sentence in order to put emphasis on 'Syria the Republic'. 


\section{Cohesive Devices in the United Nations Arabic Texts and their English} Translations: A Corpus-based Study

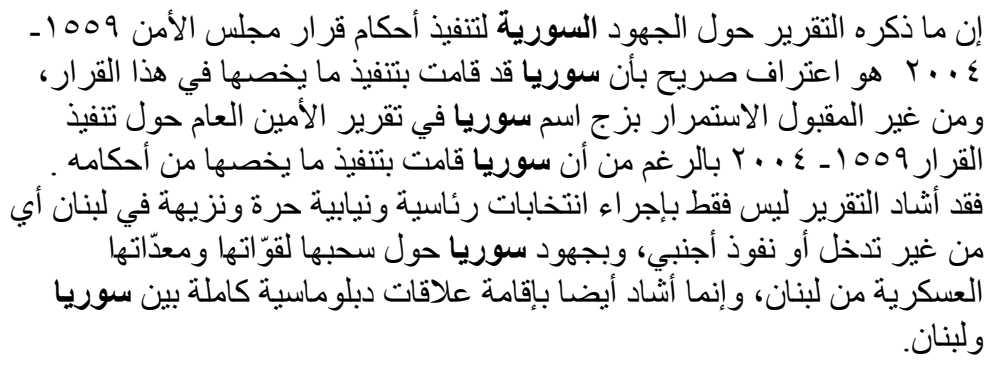

Therefore, it can be said that the semantic stability of lexical repetition, established through the connection of lexical items, is maintained throughout the text. This semantic stability relies on the precise repetition of previously mentioned items occurring at both the intra-sentential and inter-sentential levels. That is why, when repetition is abundant in both Arabic and English UN texts, the aesthetic and stylistic features of language are abandoned for the purpose of transparency and accurateness of meaning.

\section{Summary of the Results}

In the light of the above discussion, here is a summary of the obtained results:

1- The distribution of the types of cohesive devices and their subcategories is almost identical in the two languages. In terms of their frequencies, there are significant differences.

2- Considering the argumentative and descriptive nature of legal texts (United Nations texts), lexical cohesion seems to be the most frequently used cohesive device in the two languages.

3- Since legal texts require much specificity and transparency, substitution and ellipsis are considered to be marginal phenomena that may cause undesirable effects of ambiguity and misunderstanding.

4- As for conjunctive cohesion, Arabic texts are found to use additives more frequently than English. The high occurrence of these devices, especially additive $g$ wa, are due to the trend of Arabic towards coordination.

5- As for reference, Arabic seems to use a higher proportion of pronominals than English. While Arabic depends heavily on pronominals, demonstratives and contrastive reference are more frequently used in English.

6- Lexical repetition is used more frequently in Arabic than in English. As (Al-Jaber [31]) affirmed, this device contributes largely to the surface connectivity and semantic continuity of Arabic texts which 
derive much cohesion from the great redundancy resulting from lexical repetition.

\section{Conclusion}

A contrastive analysis of cohesive devices in Arabic and English United Nations texts showed that Arabic and English texts have more similarities than differences in terms of the types of cohesive devices used, whereas differences markedly occur in their frequencies. The similarities are significantly preserved for the purpose of accurateness, transparency and formality that characterise the language of legal texts. However, differences occasionally arise because of the diverse grammatical and lexical structures of Arabic and English; shifts of cohesion, therefore, occur in order to achieve the closest equivalent meaning in the translation product. This paper may help both students of translation and professionals working in law improve their discourse skills and produce more accurate translations. However, it is necessary to mention that this study attempted to shed light on some of the most prevailing patterns of cohesion; lexical collocation, for example, was not covered; hence, further research is required to address this area in more details.

\section{References}

1- Baker, M. (1993). Corpus linguistics and translation studies - implications and applications. In M. Baker, G. Francis, \& E. Tognini-Bonelli (Ed.), Text and technology: In honour of John Sinclair. (pp.233-250). Amsterdam: John Benjamins.

2- Newmark, P. (1987). A textbook of translation. London: Prentice-Hall International.

3- Baker, M. (1992). In other words: A coursebook on translation. London, England: Routledge.

4- Halliday, M.A.K., \& R, Hasan. (1976). Cohesion in English. London: Longman.

5- De Beaugrande, R.A., \& Dressler, W. (1981). Introduction to text linguistics .London: Longman.

6- Hatim, B., \& Mason, I. (1990). Discourse and the translator. London: Longman.

7- Blum-kulka, S. (1986). Shifts of cohesion and coherence in translation. In J. House \& S. Blum-kulka (Eds.), Interlingual and intercultural 


\section{Cohesive Devices in the United Nations Arabic Texts and their English}

Translations: A Corpus-based Study

communication: Discourse and cognition in translation and second language acquisition studies. (pp.17-35). Tübingen: Gunter Narr Verlag.

8- Halliday, M. A. K. (1994). An Introduction to functional grammar. China: Edward Arnold Publisher.

9- De Beaugrande, R.A., \& Dressler, W. (2002). Introduction to text linguistics .London: Longman. A Digital Printing. Retrieved from: http://beaugrande.com/introduction to text linguistics.htm

10- James, C. (1980). Contrastive analysis. London: Longman.

11- Teubert, W. (2004). Language and corpus linguistics. In M.A.K. Halliday, W.Teubert, C. Yallop \& A. Čermáková, Lexicology and corpus linguistics. (pp.73-112). London: Continuum.

12- Teubert, W. (2005). My version of corpus linguistics. International Journal of Corpus Linguistics. 10 (1), 1-13.

13- Ebeling, J. (1998). Contrastive linguistics, translation, and parallel corpora Meta: Translators' Journal, 43(4), 602-615.

14- Johansson, S. (1998). On the role of corpora in cross-linguistic research. In S. Johansson \& S. Oksefjell (Ed.), Corpora and cross-linguistic research: Theory, method, and case studies. (pp.3-24).Amsterdam: Rodopi.

15- Mauranen, A. (1999). Will 'translationese' ruin a contrastive study?. Languages in Contrast. 2 (2), 161-185.

16- Teubert,W. (1996). Comparable or parallel corpora?. International Journal of Lexicography. 9 (3), 238-264.

17- Zanettin, F. (2011). Translation and corpus design. SYNAPS- A Journal of Professional Communication. $26 / 2011$.

18- Zanettin, F. (2000). Parallel corpora in translation studies: Issues in corpus design and analysis. In M. Olohan (Ed.), Intercultural faultlines: Research models in translation studies I textual and cognitive Aspects. (pp.105-118).Manchester: St Jerome.

19- Laviosa, S. (2002). Corpus-based translation studies: Theory, findings, applications. Amsterdam: Rodopi. 
20- Fernandes, L. (2006). Corpora in translation studies: Revisiting Baker's typology. Fragmentos. 30, 087-095.

21- Johansson, S. (2003). Reflections on corpora and their uses in crosslinguistic research. In F., Zanettin, S., Bernardini, \& D., Stewart. Corpora in Translator Education. (pp.135-144). New York: Routledge.

22- Biel, Ł. (2009). Corpus-based studies of legal language for translation purposes: Methodological and practical potential. In C. Heine \& J. Engberg (Eds.) Reconceptualizing LSP. Online Proceedings of the XVII European LSP Symposium 2009, Aarhus 2010. (pp1-15).

23- Baker, M. (1995). Corpora in translation studies: An overview and some suggestions for future research. Target. 7(2), 223-243. Amsterdam: John Benjamin's.

24- McEnery, T., Xiao, R., \& Tono, Y. (2006). Corpus-based language studies: An advanced resource book. London: Routledge.

25- Granger,S. (1996). From CA to CIA and back: An integrated approach to computerized bilingual corpora and learner corpora. In Ajmer et al., (Eds) Languages in Contrast, 37-51.

26- Lauridsen, K. (1996). Text corpora and contrastive linguistics: Which type of corpus for which type of analysis?. In K. Aijmer, B. Altenberg \& M. Johannson (Eds.), Languages in contrast. Papers from a Symposium on Text-based Cross Linguistic Studies. (pp.63-72).Lund: Lund University Press.

27- Barlow, M. (1996). Analysing parallel texts with ParaConc. In Proceedings from ALLC-ACH, University of Bergen, Norway. Quoted in P. Danielsson, (2003). Units of meaning in translation - how to make real use of corpus evidence. Translating and the Computer. London: Aslib.

28- Anthony, L. (2011). AntConc Build 3.2.4. [Free computer Software Tool]. Centre for English language education in science and engineering. Waseda University: Tokyo. Retrieved February 25, 2014 from http://www.antlab.sci.waseda.ac.jp/software.html

29- Anthony, L. (2013). AntConc Build 3.4.1. [Free Computer Software Tool]. Centre for English language education in science and engineering; Waseda University: Tokyo. Retrieved February 25, 2014 from http://www.antlab.sci.waseda.ac.jp/software.html 


\section{Cohesive Devices in the United Nations Arabic Texts and their English}

Translations: A Corpus-based Study

30- Dudley-Evans, R., \& Swales, J. (1980). Study modes and students from the Middle East. ELT documents log. The British Council: London

31- Al-Jaber, A.M. (1987).Cohesion in text differentiation: A study of English and Arabic. Doctoral dissertation. University of Aston, Birmingham.

32- Williams, M.P. (1983). A problem of cohesion. In J. Swales \& H. Mustafa (Ed.) English for Specific Purposes. (pp.118-128). University of Aston, Birmingham.

33- Karakira, S. (1997). Lexis versus text: The case for translating English legal texts into Arabic. Master dissertation. The University of Western Sydney, Australia.

34- Wright, L., \& Hope, J. (2005). Stylistics: A practical coursebook. London: Routledge.

35- Koch, B.J. (1981). Repetition in discourse: Cohesion and persuasion in Arabic argumentative prose. Unpublished $\mathrm{PhD}$ dissertation. University of Michigan

36- Al-Qahtani, D.M. (2004). Semantic Valence of Arabic Verbs. Beirut, Lebanon: Libraire du Liban Publishers.

\section{Appendix}

\section{Transliteration Tables}

Transcription adopted for this paper of Arabic pronunciation as appears in AlQahtani's Semantic Valence of Arabic Verbs [36].

\begin{tabular}{|c|c|c|c|}
\hline Arabic Alphabet & Symbols & Arabic Alphabet & Symbols \\
\hline 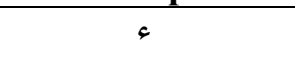 & $?$ & ض & $0 \mathrm{~d}$ \\
\hline ب & $\mathrm{b}$ & b & $0 \mathrm{t}$ \\
\hline 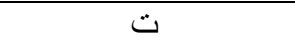 & $\mathrm{t}$ & b & D0 \\
\hline$\dot{H}$ & $\mathrm{~T}$ & $\varepsilon$ & .c \\
\hline ج & $\mathrm{Z}$ & $\dot{\varepsilon}$ & ${ }^{\wedge} \mathrm{g}$ \\
\hline
\end{tabular}


Imen CHAALAL

\begin{tabular}{|c|c|c|c|}
\hline$\tau$ &.$h$ & ف & $\mathrm{f}$ \\
\hline$\dot{\tau}$ & $X$ & ق & $\mathrm{q}$ \\
\hline د & $\mathrm{d}$ & ك & $\mathrm{k}$ \\
\hline$\dot{j}$ & $\mathrm{D}$ & J & 1 \\
\hline נ & $r$ & r & $\mathrm{m}$ \\
\hline j & Z & ن & $\mathrm{n}$ \\
\hline س & $\mathrm{S}$ & 0 & $\mathrm{~h}$ \\
\hline ش & $\mathrm{S}$ & و & W \\
\hline ص &.$S$ & ي & $\mathrm{j}$ \\
\hline
\end{tabular}

Table 1: Consonantal Symbols

\begin{tabular}{|c|c|c|}
\hline \multicolumn{2}{|c|}{ Vowels } & \multirow{2}{*}{$\begin{array}{c}\text { Symbols } \\
\mathrm{a}\end{array}$} \\
\hline Short & 5 & \\
\hline & 8 & $\mathrm{u}$ \\
\hline & ध & $\mathrm{i}$ \\
\hline \multirow[t]{3}{*}{ Long } & 1 & $\mathrm{a}:$ \\
\hline & g & $\mathrm{u}:$ \\
\hline & ي & i: \\
\hline
\end{tabular}

Table 2: Vocalic Symbols 
Cohesive Devices in the United Nations Arabic Texts and their English Translations: A Corpus-based Study

\section{NOTES}

1 - http://documents.un.org/

2- Blend words and numbering references do not appear in Halliday and Hasan's classification [4], but it is very important to mention their occurrence since they are attributed to the language of UN texts.

3 - For the transliteration tables see the appendix. 